\title{
Introduction to Special Issue on Geosynthetic-reinforced pile-supported embankments
}

\author{
S.J.M. van Eekelen ${ }^{1}$ and J. Han $^{2}$ \\ ${ }^{1}$ Geotechnical researcher and adviser at Deltares, Department of Geo-engineering, PO box 177, $2600 \mathrm{MH}$ \\ Delft, Netherlands, E-mail: suzannevaneekelen@deltares.nl \\ ${ }^{2}$ Professor, Civil, Environmental, and Architectural Engineering (CEAE) Department, The University of \\ Kansas, 2150 Learned Hall, 1530 W. 15th Street, Lawrence, KS 66045, USA, e-mail: jiehan@ku.edu
}

\section{SPECIAL ISSUE ON GEOSYNTHETIC-REINFORCED PILE-SUPPORTED EMBANKMENTS}

Volume 27, no. 2 of Geosynthetics International is a special issue devoted to geosynthetic-reinforced pilesupported (GRPS) embankments. A geosyntheticreinforced pile-supported embankment consists of a reinforced embankment with one or multiple horizontal layers of geosynthetic reinforcement installed at the base of the embankment over a pile foundation in soft soils.

GRPS embankments have become an effective and economic solution for mitigating soft soil - related problems and risks when embankments are constructed on soft soils to support highways, railways, storage tanks, industrial areas, and even buildings. GRPS embankments have been constructed in soft soil areas worldwide because they offer several advantages over alternative solutions, such as short construction time, elimination of staged construction, small post-construction settlement, limited influence on nearby objects, and limited or no maintenance requirements.

A significant amount of research has been conducted by many researchers and engineers in the past three decades to advance this technology by better understanding their behavior through laboratory and field studies including instrumentation and monitoring and numerical analyses, and by improving their design and construction.

The First International Workshop on GeosyntheticReinforced Pile-Supported Embankments was held at Tongji University, Shanghai, China from June 14 to 16, 2017 with the objectives: (1) to understand current practices and research in different countries, (2) to seek consensus or identify differences in common issues, (3) to identify topics for future research, and (4) to explore opportunities for future collaborations. The invited international experts participating in this workshop were: C. Xu (chair), X. Bian, R. Chen, S. Liu, R. Rui, F. Xiao, G. Zheng, J. Zheng, and Y. Zhuang from China; J. Han (chair) and J. Collin from USA; S. van Eekelen (chair) from Netherlands; S. Liyanapathirana and L. King from Australia; M. de Souza Soares de Almeida and M.C.F. Almeida from Brazil; M. Blanc from France; S.J. Hao from Malaysia; and B. Reshma from India. Approximately 70 people participated in this workshop. The workshop was organized by Tongji University, funded by the Ministry of the China Changjiang Scholars Fund and the National Natural Science Foundation of China (No. 51478349), and sponsored by the industrial partners: Maccafferi, Tencate, Tianan Road Engineering Materials, Hock Technology, and NETE.

This special issue on GRPS embankments was prepared after the workshop to include extended papers on work presented at the workshop, manuscripts written by invited experts, and manuscripts received independently by the journal on the same theme. The total number of the manuscripts received was 16 , from which 12 technical papers and 2 technical notes were accepted for publication after review. Each manuscript received rigorous peer review by two or more anonymous reviewers in addition to the two guest editors.

This special issue starts with a state-of-the-art paper by the guest editors that covers a wide range of topics including: load distribution, deformations, and their key influence factors (such as cyclic loading, pile layout, and crust effects); long-term field performance; detailed review of design methods; stability; and topics for future research.

We would like to thank the Editor, R.J. Bathurst, and the Chair of the Editorial Board, J.P. Giroud for providing us the great opportunity and excellent guidance to co-edit this special issue. We express our appreciation to C. Xu for his great efforts to organize the First International Workshop on Geosynthetic-Reinforced Pile-Supported Embankments.

This special issue would not have been possible without the outstanding technical contributions of all the authors and the careful and constructive reviews provided by all the anonymous reviewers who ensured each paper met the high technical and presentation standards of Geosynthetics International.

It was our great pleasure to work with all the authors as guest editors of this Special Issue and to collaborate on our joint state-of-the-art paper. 